\title{
Comparative Study of Literary Forms in English Entertainment News at Home and Abroad in Internet Era
}

\author{
Guo'e Yan \\ Hebei Institute of International Business and Economics, Qinhuangdao, Hebei 066311, China
}

Keywords: Internet, English entertainment news, Stylistic analysis, Comparative study.

\begin{abstract}
This article is mainly to do comparative study of literary forms in English entertainment news at home and abroad in Internet era. By simple elaborating and analysis to such aspects as arrangement characteristics, vocabulary usage, language style, language construction, etc. of entertainment news in the websites at home and abroad, it is to make clear about the differences and similarities between them, enhance readers' cognition degree to network English entertainment news, master more English reading skills and understand cultural backgrounds and differences between China and foreign countries so as to enrich literary forms of English entertainment news, promote translation competence and bring more information for the public.
\end{abstract}

\section{Introduction}

The $21^{\text {st }}$ century is an Internet era. Internet has become an important part in our daily life, which is inseparable with our work, study and entertainment. Under such historical background, media at home and abroad begin to attach importance to the design and development of English news websites so as to provide more information to people and expand ways of news gain. And at present, the entertainment news is the contents with higher concern extent. The entertainment news has its own characteristic, high entertainment and artistry, receiving people' $s$ attention, with some news value. Therefore, it is worthwhile to study the stylistic characteristics of English entertainment news in the Internet era. Due to the difference of news reports at home and abroad, the literary forms of English entertainment news are different. The simple comparative study could help readers to better get information.

\section{Characteristic of English Entertainment News in Edit Type-setting in Internet Era}

The edit type-setting is an important aspect of the stylistic characteristics of English entertainment news in Internet era. The distinction in edit type-setting would cause different communication effects. Different arrangement characteristics in English entertainment news would also bring different feelings to readers and make them pay attention to different information. Thus, the English entertainment news report in the Internet era must pay attention to the edit type-setting, guarantee its quality and make scientific and reasonable design. The edit type-setting would be different according to different news types and that of entertainment news has its own characteristic. Usually, it needs to highlight particularity of entertainment news to get better reading effect. We could study from the following aspects:

\section{To Use Pictures Greatly}

The development of Internet has integrated in people' $s$ daily life which pays attention to information on the Internet all the time. The public has bigger and bigger demand to Internet 
information. The particularity of Internet makes people makes reading more like the fragment reading. Therefore, people are not satisfied with text information any more but pay more attention to picture information which could help users to quickly know the key point and give an insight into the reported entertainment news. Using lots of pictures would help readers with saltatory reading to quickly browse relevant contents. Survey finds that if journalists use pictures or videos during edit type-setting, it would get more attentions and attract more readers than the text report. Both Chinese media and foreign media realize the significance of pictures in the English entertainment news report. Thus they would use lots of pictures in daily edit, which is also the common characteristic between them.

\section{Setting of Paragraph Length}

How to set the paragraph length of literary forms in English entertainment news in Internet era is very important. Paragraph could reflect journalists' editing characteristic in contents, showing their logical thought and narrative ability. Paragraph could be clear at a glance, with strong visuality. Therefore, it must attach importance to the setting and arrangement to paragraph during arranging English entertainment news. Good paragraph could help people make clear about interior structure of the whole news report. Reading on the Internet more tends to be fast reading. With the gradual acceleration of people' s pace of life, the public like the news report with clear structure more in which they could fast get what they want to know, saving time and meanwhile grasping important contents. Under such case, English entertainment news with short length is more popular, while the traditional English entertainment news with long literary piece is not suitable in the Internet era. By studying the famous websites at home and abroad, we find that foreign media prefer English entertainment news with long literary piece while the domestic media like the shorter ones.

\section{Good at Using Punctuations}

During the editing of English entertainment news report on Internet, an important characteristic is the usage of punctuations. Many people would ignore their function. In fact, the usage of punctuations would directly affect reading experience. Though punctuations are the small part in literary forms, mainly for helping role, rational usage of punctuations could make article even better. They have some influence to the whole reading of an article, especially in the English entertainment news. There are many kinds of punctuations. Different punctuations mean different moods, with different functions. Also, the change of their location would cause variation in meaning of English entertainment news. From the aspect of foreign English entertainment news, it's no big deal that there are some differences. As to the usage of punctuations, the usage rate of foreign media is lower while domestic media use them more frequently.

\section{Characteristic of English Entertainment News in Vocabulary Usage and Language Style in Information Era}

When studying the stylistic features of English entertainment news in Internet era, we need also to discuss from two aspects such as vocabulary usage and language style. With the development of English entertainment news, its vocabulary usage and language style would form particular characteristic, study to which is to better know English entertainment news, promote its development, reinforce readers' understanding to English entertainment news and cultivate their love and interest.

\section{Relevant Characteristics of Vocabulary Usage}

English entertainment news in Internet era mainly uses words, which is the basic sentences construction. Too complicated or formal words in English entertainment news are not good for readers to read, which would decrease readers' interest. When editing English entertainment news, vocabulary usage must be paid attention. Appropriate words could not only provide information to readers but also make readers become interested. 
There are three aspects needed attention when using vocabulary:

Firstly, the skillful use of vague words. The traditional media news has higher requirements to accuracy of words which always follow the accuracy principle. However, in the network era, many ambiguous words appear. Skillfully using vague words in English entertainment news is good to enhance authority of uncertain events, making them with bigger persuasion. Comparing those English entertainment news in domestic websites and foreign websites, it could find that foreign media use more vague words than China.

Secondly, the use compound words. When editing the English entertainment news on Internet, it should use more compound words, because they may enrich the news report and make the article more abundant. Using many compound words could better express information and help readers to quickly understand. Throughout those media English websites at home and abroad, it finds that both use many compound words in English entertainment news.

Thirdly, as for the length of vocabulary, the foreign media use longer vocabulary in English entertainment news than Chinese media. Generally speaking, English vocabularies used by foreign media are more complicated, with longer vocabulary, which make readers more difficult to understand. Comparing to the foreign English entertainment news, Chinese media use shorter vocabulary which is simple and clear, convenient for people to read and know relevant entertainment information.

\section{Difference in Language Style}

Most English entertainment news in China has Chinese-style means of expression and language style, which is so called "Chinglish" . The so called "Chinglish" means that there is no problem in vocabulary usage and sentences expression, but its final presented form tends to be Chinese style, with obvious Chinese characteristics. Such characteristic of language style makes English entertainment news in China with more characteristic so that foreign media would accurately know this is from China. From the dialectical aspect, such language style may let those foreign media who are not familiar with China think that China is not good enough at reporting English entertainment news.

With English as the native language in most western countries, foreign media could better use this language in the report of English entertainment news and effectively give play to the linguistic flexibility. They would handle the language structure with high proficiency. They can not only write "standard English" but also reflect linguistic charms in style.

For example, when reporting entertainment news, Daily Mirror always adopts short article paragraphs, many pictures, more vivacious language style and be colloquial as much as possible. Thus it is very popular among the public.

\section{Characteristic of English Entertainment News in Construction in Information Era}

By comparative study of the stylistic features of English entertainment news in Internet era, we should also analyze the whole structure of article. Different structures would bring different feelings to readers, which can be analyzed from sentence structure and text structure. As for domestic news media, English is not the native language. Thus its sentence structure and text structure would directly affect readers' reading effects. Analyzing this could help English fans to appreciate English entertainment news from multiple aspects.

\section{To Adopt Sentence Structure}

When studying English, the most bases are the word and vocabulary. And terms make up sentence. However, sentence is not the connection of several words at will, but needs to follow some principles, especially in English entertainment news. The simple connection of words would make readers feel puzzled and have problem in understanding. Thus when we study the literary forms of English entertainment news, we must analyze its sentence structure. It mainly includes two parts, the 
structures in syntactic level and the choice of voice. Comparing the English entertainment news at home and abroad, we could easily find that foreign media like to use compound sentences more while domestic media like the simple sentences. Such difference is due to the different cultural backgrounds. The different English language environments make different applications of sentence structures. As for the choice of voice, both prefer subjectification and use active voice which could better convey entertainment information to readers.

\section{The Choice of Texture Structure}

A saying goes that, "One thousand readers will see one thousand Hamlet." There is interaction between English entertainment news and readers. To same news text content, different readers would have different feelings and receive different information, with different concerns. When analyzing text structures of literary forms in English entertainment news at home and abroad in Internet era, we could elaborate from the following aspects:

Firstly, some serious news such as political news, city news, etc. would have long length, reflecting their seriousness and formality. As for the entertainment news, it is for entertainment and not so serious like political news. Thus it would have short length to avoid formality and monotonicity which would affect readers' interest. Comparing the English entertainment news at home and abroad, we could find that foreign English entertainment news would have longer length, more complicated and abundant use and expression of language, more concerns to control the details, helping readers to get more detailed information. However, such long-length news would also bring disadvantages, to affect readers' reading efficiency and generate fatigue.

Secondly, during comparative study, we find that both domestic and foreign English entertainment news would follow time sequence to carry our report and usually adopt narrative structure to enhance readers' reading comprehension level and reduce reading disorder. In addition, narrative structure is good for readers to know the beginning and end of the event, realizing better spread.

In a word, the English entertainment news at home and broad in Internet era have their own characteristics, with both intercommunity and difference.

\section{Conclusion}

Under the background of Internet era, information technology becomes more and more advanced, with deeper informationization degree. Network provides convenience for people' $s$ life, help people to gain information whenever and wherever possible and open up people' s horizons. English is an international language and significant language for international communication. Therefore, combination of network and English is also the trend and tendency of era development. In order to adapt networked development, traditional media also establish their own official websites and set up English entertainment news report column, which is of great significance to take in global information and move towards internationalization. The entertainment news is always hot contents that people pay attention, poplar in the public. In order to help the public gain more entertainment information, both domestic and foreign media keep perfecting their English entertainment news report, expanding range and thus forming their own unique stylistic features. Doing comparative study to the literary forms of English entertainment news in Internet era is good for the stable development of English entertainment news.

\section{References}

[1] Zhou Danting, Comparative Study of Literary Forms in English Entertainment News in Internet Era. Northwest University, 2015.

[2] Yu Xiaoning, Comparative Analysis of Linguistic Features in English Entertainment News in China and America. Dongbei University of Finance and Economics, 2010. 
[3] Li Zhongqiang, English Translation of Chinese News under the Background of New Media. Shanghai International Studies University, 2012.

[4] Ma Wenli, Discourse Analysis of Chinese Contemporary English Paper. Wuhan University, 2010.

[5] Li Mengdi, Comparative Analysis of Thematic Stricture of English and Chinese Entertainment News Jilin University, 2009. 